\title{
A PERSONAL SERIES OF COMMON ABDOMINAL EMERGENCIES
}

\author{
Robin BUrkitT, M.A., M.D., F.R.C.S., F.R.C.S.I. \\ Upton Hospital, Slough
}

A PERSONAL series of cases offers certain advantages. When all cases have had their surgery performed at the same hospital by the same surgeon under relatively static conditions, there is an absence of many of the variables which interfere with a purely objective collection of cases. Memory is also able to keep a rough check on the fallibility of every system of records. The present series consists of 'common' abdominal emergencies treated by the author at Upton Hospital, Slough, during an eight-year period from 1954 to 196r. The series only includes those cases who have undergone surgery, and 'common' has been arbitrarily taken to include all those conditions of which ten or more have been seen during the period under review.

Surgery is not just cutting, and before commencing to describe this series the author would like to say a few words regarding his surgical philosophy. Bad surgery often cannot be helped, but unnecessary surgery, where this results from slipshod and careless diagnosis, is inexcusable. Although true of all sorts of surgery, this is especially true of emergency, where it is all too easy to take the line of least resistance, and 'have a look'. Whoever coined that dreadful aphorism, ' better to look and see than to wait and see ', did no good to surgery. Many an acute appendix, for instance, can be confidently diagnosed by a single touch of the abdomen-or even from the end of the bed, where the flushed face, fœit breath and coated tongue point to the black appendix. This is not by any means always the case, and in the difficult pelvic appendix in the child, the retrocæcal appendix in the stout middle-aged man, the vague and uncertain symptoms in the aged, the surgeon who does not seek what help he can from his X-ray and pathological departments is totally unfair to his patients; and fortunate, indeed, are those of us who work in hospitals where these two departments are always ready and willing to help at any hour of the day and night. This aim to avoid unnecessary emergency surgery curtails drastically the number of emergency operations described in this paper; 62 cases of strangulated hernia may seem a very small number for eight years' hard work as an emergency surgeon.
Despite the alleged dangers of so doing, we ats ways attempt reduction before considering surs gery, and are successful in nearly $50 \%$ of caseg With gentle technique complications are minimat and with careful supervision those which do occir present no problem. Only one case of reduction en masse occurred during this period, and symptoms persisted operation was carried ot without undue delay and without untowar results. The advantages of such an approach mas secm questionable; but in frail elderly patients who are so often the victims of this disease, a quiet hernial repair performed when all obstruø tion has subsided carries a very different mortalit from operative repair of the strangulated hernis There are other types of acute obstruction, too where surgery should be avoided whengुg possible. The patient who is known to have multiple adhesions can often be treated with operation, and most important of all there is the case of the early post-operative obstruction. Thi is one of the most worrying conditions in surger: hence the variety of techniques described for is treatment. We have found, however, that surgerf is very rarely necessary in these cases. Whe everything seems to point to the inevitability of operative intervention, it takes considerablo courage to hold one's hand, but confidence grows with the years, and it is a striking fact that not single case of early post-operative obstructio came to surgery on this unit during this eight-year. period, and no case died of this condition. Con@ servative treatment was, in fact, $100 \%$ successfuß One hears of the 'heroic' surgeon, but from the surgeon's point of view surgery always requires the least heroism. The only hero of an operatio is the patient.

Acute pancreatitis and acute cholecystitis are again absent from this series as we do not feel than there is any place for immediate surgery in these conditions. The only place for surgery in acute pancreatitis is when the diagnosis is in doubt and the only place for surgery in acute cholecystitis iิ when the gall-bladder has ruptured, or seems in imminent danger of doing so. All cases of acut巴 cholecystitis that have come into this unit during the past eight years have received initial conserva 
tive treatment, and in only a very small number was operation required before the acute attack had subsided. That gall-bladders do rupture during conservative treatment is not denied, but this should rarely, if ever, be allowed to happen. If symptoms are not subsiding after a few days, surgery can then be undertaken. Adopting this treatment, there were no fatal cases of acute cholecystitis during the period under review, and the only perforated gall-bladders seen had perforated before and not after entering hospital.

We are not suggesting that there is anything specially hazardous about removing the acutely inflamed gall-bladder in an otherwise healthy patient, but acute cholecystitis occurs commonly at two stages of life when one does not want to operate unnecessarily - the late stage of pregnancy and very advanced age. At the time of writing we have two old ladies in our wards, one aged 87 and the other 89 , who are waiting to go home, having recovered from severe attacks of acute cholecystitis.

Mesenteric occlusion is another of those conditions which, although occurring comparatively frequently, does not appear in the series, for the reason that there are very few cases for whom surgery has really anything to offer. Either they are so mild that they will recover spontaneously, or so ill that they will never stand a major resection. To operate on such cases when they are obviously too ill to stand major surgery is a complete waste of time. The only recoveries we have had in cases of mesenteric occlusion during this period have been in cases where the gut appeared to be sufficiently viable to be left alone-who recovered, in fact, in spite of and not as a result of surgery! On only one occasion have we had complete success following extensive resection for mesenteric occlusion, and on that occasion the occlusion was not due to any cardiovascular disease, but to a carcinoid tumour at the root of the mesentery. We resected nearly 6 feet of gangrenous small intestine, and the patient is alive and well ten years later. There was one interesting case during this period, when operation was performed on a man of 78 years whom we diagnosed clinically as a case of mesenteric occlusion. To our surprise we found no abnormality within his peritoneal cavity. The abdomen was closed. His condition deteriorated and he died four days later. At autopsy his entire small intestine was found to be gangrenous due to a superior mesenteric occlusion!

In conclusion we should like to stress the fact that surgery must never be performed by rule-ofthumb. Every case is different, just as every person is different, and before any operation a surgeon must carefully decide whether the advantages offered by surgery are in fact greater than the advantages offered by leaving the cure to Mother Nature, who has an extraordinary way of often curing the apparently incurable conditions.

\section{The Series}

Children under the age of Io years, gynæcological emergencies and gastrectomies for gastroduodenal hæmorrhage are all excluded from this series; the first because the hospital does not include a pædiatric unit and the number of children admitted is not sufficiently great to be of any value in this review, the second because these cannot be considered to be in a general surgeon's 'terms of reference', although a very large number of them find their way into his beds, and the third because although these are 'emergency' operations they are not really ' acute abdomens' in the accepted sense.

\section{Acute Appendicitis}

There were 721 operations for acute appendicitis with six deaths; five of these were the result of fulminating peritonitis in middle-aged or elderly patients. The sixth was in a young girl of 24 , who developed acute appendicitis in the last month of pregnancy. A gangrenous appendix was removed, and her immediate progress seemed highly satisfactory. A week after the operation she went into labour and delivered herself spontaneously of a live baby. The following day she developed a fulminating toxæmia which resisted every form of treatment, and she died three days later. This was the only fatality in the 631 cases of acute appendicitis that occurred in patients under the age of 50 .

Initial conservative treatment was adopted for all cases of appendix abscess, with no untoward results.

The results according to age appear in Table $\mathbf{I}$.

TABLE I

ACUTE APPENDicitis

\begin{tabular}{|c|c|c|c|c|c|}
\hline$\overline{\text { Age }}$ & & Males & Females & Total & Deaths \\
\hline $\begin{array}{l}10-19 \\
20-29\end{array}$ & * & $\begin{array}{r}104 \\
70\end{array}$ & $\begin{array}{l}152 \\
108\end{array}$ & $\begin{array}{l}256 \\
178\end{array}$ & - \\
\hline $30-39$ & . & 68 & $\begin{array}{r}59 \\
59\end{array}$ & $\begin{array}{l}170 \\
127\end{array}$ & - \\
\hline $40-49$ & .. & 47 & 23 & 70 & - \\
\hline $50-59$ & .. & $3 \mathrm{I}$ & 15 & 46 & I \\
\hline $60-69$ & .. & I 5 & 7 & 22 & 2 \\
\hline $70-79$ & .. & IO & 10 & 20 & I \\
\hline $80-89$ & .. & & I & I & I \\
\hline $90-99$ & . & 一 & I & I & - \\
\hline Total & .. & 345 & 376 & 721 & 6 \\
\hline
\end{tabular}

This table shows a fairly steady fall in numbers from adolescence onwards, as one would expect, 
as acute appendicitis is generally rightly regarded as primarily a disease of the young. If, however, these figures are corrected in accordance with the 1961 Registrar General's Population Estimates an interesting feature is noticed. The figures fall even more regularly up to the age of 70 , but after this age, where there is a marked fall in the general population, the relative frequency of acute appendicitis suddenly increases so that it is almost twice as frequent in the eighth decade as in the seventh.

Regarding the management of acute appendicitis there are two points that we should like to make. In th's first place, despite the current trend against the routine use of antibiotics, we administer these drugs in all cases of acute appendicitis where there is evidence of general peritonitis, and are absolutely convinced that this is the reason for the remarkably low incidence of complications in this series. In only one case was further surg'ry necessary in order to drain a pelvic abscess that had ruptured into the general peritoneal cavity. Every other pelvic abscess subsided on conservative treatment, drainage through rectum or vagina never being employed.

\section{Perforated Peptic Ulcer}

There were $8 \mathrm{I}$ cases of perforated peptic ulcer -71 males and ro females. The average age of the males was 50, of the females 6o. All perforations in the region of the pylorus were classified as 'duodenal', the term 'gastric' being confined to ulcers on the lesser or greater curves or body of the stomach. Of the 71 males, there were 68 duodenal perforations, two gastric perforations and one perforated anastomotic ulcer. The solitary operation for perforated anastomotic ulcer does not indicate that only one such case occurred in eight years, but that we normally treat such cases conservatively. The perforated anastomotic ulcer is usually well sealed off and responds excellently to non-operative treatment, which is to be preferred if possible as later definitive surgery will probably be required. The ten female cases consisted of five duodenal and five gastric perforations. Gastric ulcers thus accounted for $50 \%$ of the female cases, as opposed to only $2.8 \%$ of the males. The relative frequency of perforations in males as compared to females was $8: \mathrm{I}$. In a previous unpublished series collected by the author this relative incidence was identical.

Perforations were all treated by simple closure or partial gastrectomy with two exceptions-the anastomotic ulcer, already discussed, and the posterior perforation which appeared clinically to be sealed off and which was also treated conservatively. Simple suture was the standard treat- ment, emergency gastrectomy being reserved fơ those cases who, on clinical grounds, had reache that stage in their ulcer history when gastrectom 9 was inevitable, whether they had or had not perforated, provided they appeared to be in a condition to stand major surgery. In our opinio $\vec{Z}$ indiscriminate partial gastrectomy for perforateg peptic ulcer is an entirely unwarranted proceduren. It results in many young men undergoing partian gastrectomy who may well have remained withouf symptoms for several years. There is also afp economic factor to be considered, as certain in $\vec{e}$ dustrial concerns are reluctant to give importani executive posts to men who have undergons gastrectomy. They regard them, rightly of wrongly, as potential liabilities.

In the present series 22 cases were treated b. emergency gastrectomy, and the remaining 59 bys simple closure. Of the cases treated by gastrec $\$$ tomy there were two deaths. One was a knowi ' cardiac' and was under treatment in the medicat wards for a severe hæmatemesis when perforation occurred. Although he appeared to make a good recovery from operation, he developed congestive heart failure from which he died. The secon $\Phi$ was a young man of 33 who died of cardiac arres on the operating table. This was found at autogsy to be due to bilateral phæochromocytomata of adrenal medulla of which we were unfortunatis in ignorance. Among the 59 simple closures there were four deaths. One was a man of 70 who has a massive hæmatemesis ten days after his operaอ tion, and died almost instantaneously. One wå a lady of 73 who was in hospital for treatment op a fractured femur when she had a large hæma $\vec{\not}$ temesis. This was followed by a perforation, and she had little hope from the start. The third was a man of 72 who lived alone and was found in collapsed state in his house. He had obviouslye been ill for several days, and was moribund ap. the time of admission. Operation was performed and his abdomen drained, but he never regained consciousness. The fourth was a man of 6r who died of a fulminating peritonitis for which nơ satisfactory cause could be found. Thus of the 8I cases of perforated peptic ulcer, although there were in fact six deaths, only one of these really stood any chance of survival.

Table 2 shows the results according to age.

Associated Perforation and Hæmorrhage

Perforation and hæmorrhage occurring simuleo taneously is always serious, and seems to bed almost confined to elderly people. There were ${ }^{+}$ six cases in this series, five of whom were over 700 Two cases perforated who were already under medical treatment for severe hæmorrhage. Both?ִ 
TABLE 2

Perforated Peptic Ulcer

\begin{tabular}{|c|c|c|c|c|c|}
\hline Age & & Males & Females & Total & Deaths \\
\hline $20-29$ & . & 3 & - & 3 & - \\
\hline $30-39$ & .. & 14 & 2 & 16 & I \\
\hline $40-49$ & .. & 15 & I & 16 & - \\
\hline $50-59$ & . & I 7 & 2 & 19 & I \\
\hline $60-69$ & 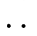 & 12 & I & 13 & I \\
\hline $70-79$ & .. & 8 & 2 & 10 & 3 \\
\hline $80-89$ & . & 2 & 2 & 4 & - \\
\hline Total & .. & 71 & 10 & $8 \mathrm{I}$ & 6 \\
\hline
\end{tabular}

succumbed. The remaining four had a severe hæmorrhage approximately one week after simple closure of a perforation, and in every case it was found to be a posterior ulcer which had bled, while it had been a separate anterior ulcer which had perforated. One of these collapsed and died instantaneously. The other three, aged 73,76 and 77 , were treated by emergency gastrectomy and all made uneventful recoveries. It is surprising how well very old people seem 10 tolerate gastrectomy, in spite of a poor start, while they tolerate small intestinal resection very badly indeed. This is, of course, especially the case if the small intestine is obstructed.

\section{Acute Intestinal Obstruction}

Acute intestinal obstruction is the Cinderella of emergency surgery. There were 120 cases in the present series with 23 deaths-a mortality of almost $20 \%$. This may seem appallingly high, but the answer is not far to seek. Owing to its insidious onset, obstruction reaches hospital late. The dramatic textbook description of the acutely obstructed bowel is rarely seen. Time after time we have watched the amazement on the face of a young house surgeon as we have demonstrated a gangrenous Richter's hernia in a patient whose symptoms seemed to him hardly sufficiently severe to justify exploration. This is especially the case with old people amongst.whom there is an added delay because their courage and fortitude so often result in their complaining little and summoning the doctor late. Thus they all too often reach hospital with a gangrenous loop of gut, and fail to survive resection. Whether it is the operation or the obstruction that kills them is impossible to say. Regarding the management of cases of strangulated hernia, there are two points the author would like to make. In the first place we should like to emphasize the vast superiority of Professor A. K. Henry's mid-line extraperitoneal approach to that of any other approach for the strangulated femoral hernia. For several years we have employed this approach to the exclusion of all others in the treatment of both simple and strangulated femoral hernia, and have been thoroughly satisfied with the results. There is only one form of femoral hernia where it is unsatisfactory. This is the small irreducible femoral hernia, where the irreducibility is due, not to the contents of the sac, but to the presence of fibro-fatty tissue in its wall. These herniæ are quite easy to detect clinically; they are freely mobile, and feel exactly like a gland-which they often turn out to be! They are best approached directly.

The other point in the management of the strangulated hernia concerns the case of a doubtfully viable bowel-to resect or not to resect. In elderly patients we think it best to give them the benefit of the doubt, and leave the bowel alone. They stand resection badly. In younger patients it is probably better, when in doubt, to resect. We have had two cases in whom conservative treatment was wrongly carried out, but fortunately both recovered. The first was a Richter's femoral hernia. The loop appeared viable, and no resection was carried out. A week later the patient suddenly developed all the appearances of generalized peritonitis due to perforation of an abdominal viscus. At operation a small perforation was found at the site of the constriction. Resection was performed and recovery was uneventful. The other was a middle-aged man who had an internal hernia due to a band. The segment involved was very congested but appeared viable. No resection was carried out and recovery seemed uneventful. Five months later he was readmitted with an acute-on-chronic intestinal obstruction. At operation a small gut obstruction was found, due to a narrow pipe-stem segment of small intestine at the side of the previous internal hernia. Presumably this was due to an avascular necrosis. An interesting point was that it looked like the fibrotic stage of Crohn's disease, and the pathologist, who had not been given the clinical history, reported it as being very similar to regional ileitis in histological appearances.

The 120 cases of acute intestinal obstruction included 62 cases of strangulated hernia and 58 from other causes. The strangulated herniæ for whom immediate surgery was required were distributed as follows:

$\begin{array}{lcccc}\text { Inguinal } & \ldots & \ldots & \ldots & 27 \\ \text { Femoral } & \ldots & \ldots & \ldots & 26 \\ \text { Umbilical } & . & . & \ldots & 5 \\ \text { Interstitial } & \text { inguinal } & \ldots & \ldots & 3 \\ \text { Incisional } & \ldots & \ldots & \ldots & 1\end{array}$

The other 58 cases of acute intestinal obstruction were distributed as follows: 


\begin{tabular}{|c|c|c|c|c|}
\hline & Cases & Deaths \\
\hline \multirow{5}{*}{\multicolumn{3}{|c|}{$\begin{array}{l}\text { Bands and adhesions } \\
\text { Primary carcinoma of large bowel } \\
\text { Primary tumour of small bowel } \\
\text { Secondary tumour of small bowel } \\
\text { Volvulus of large bowel }\end{array}$}} & 27 & 5 \\
\hline & & & 14 & 4 \\
\hline & & & I & - \\
\hline & & & 5 & 2 \\
\hline & . & .. & 4 & $\mathbf{I}$ \\
\hline Foreign bodies $\quad$. & . & . & 4 & - \\
\hline Stenosis of small bowel & $\ldots$ & .. & 2 & - \\
\hline Regional ileitis $\quad \ldots$ & . & . & $\mathbf{I}$ & - \\
\hline
\end{tabular}

Of the four foreign bodies, one was a gallstone, one a stone that had become dislodged from a jejunal diverticulum, while the remaining two were masses of undigested food material. Of the two cases of small bowel stenosis, one followed an internal hernia, and has already been described. The other followed an end-to-end anastomosis for strangulated hernia that had been carried out elsewhere a year previously. The single primary tumour of the small intestine that caused obstruction was a neurofibroma.

Tables 3 and 4 show the age-incidence of acute intestinal obstruction.

TABLE 3

Strangulated Hernia

\begin{tabular}{|c|c|c|c|c|c|}
\hline \multicolumn{2}{|c|}{ Age } & Males & Females & Total & Deaths \\
\hline $10-19$ & .. & - & - & - & - \\
\hline $20-29$ & . & - & $\mathbf{I}$ & I & - \\
\hline $30-39$ & .. & $\mathbf{I}$ & $\mathbf{I}$ & 2 & - \\
\hline $40-49$ & . & 4 & - & 4 & - \\
\hline $50-59$ & . & 7 & I & 8 & - \\
\hline $6 o-69$ & . & 10 & 6 & I 6 & 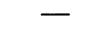 \\
\hline $70-79$ & . & I I & 8 & 19 & 4 \\
\hline $80-89$ & .. & 4 & 4 & 8 & 3 \\
\hline $90-99$ & . & 2 & 2 & 4 & 3 \\
\hline Total & . & 39 & 23 & 62 & 10 \\
\hline
\end{tabular}

TABLE 4

Other Cases of Acute Intestinal Obstruction

\begin{tabular}{|c|c|c|c|c|c|}
\hline \multicolumn{2}{|c|}{ Age } & Males & Females & Total & Deaths \\
\hline $10-19$ & $\ldots$ & - & I & I & - \\
\hline $20-29$ & $\cdots$ & I & 2 & 3 & 一 \\
\hline $30-39$ & $\cdots$ & 3 & 2 & 5 & - \\
\hline $40-49$ & . & 5 & 2 & 7 & 一 \\
\hline $50-59$ & $\cdots$ & 5 & 9 & 14 & I \\
\hline $60-69$ & .. & 3 & 7 & 10 & 4 \\
\hline $70-79$ & $\ldots$ & 5 & 8 & 13 & 5 \\
\hline $8 o-89$ & $\ldots$ & I & 2 & 3 & - \\
\hline 90-99 & $\cdots$ & - & 2 & 2 & 2 \\
\hline Total & $\ldots$ & 23 & 35 & 58 & I 2 \\
\hline
\end{tabular}

\section{Perforated Diverticulitis of Colon}

There were 27 cases of perforated diverticulitis of the colon-six of the proximal colon and 21 of the distal colon. Perforation of the proximal colon or cæcum is, of course, an entirely different disease from perforation of the distal colon. The diverticulum of the cæcum is probably congenital in all cases, and perforation is therefore likely any age. The six cases in this series varied in a from 12 to 62 years. Clinically a diagnosis of acute appendicitis is always made, and if one is nøt well acquainted with the condition the appearanc $\overrightarrow{\vec{E}}$ after opening the abdomen will often make ope change one's diagnosis to carcinoma of the cæcu and perform a hemi-colectomy. In our exper ence the diverticulum most often lies on the postero-lateral aspect of the cæcum, beneath the peritoneum, and the perforation is immediatefy covered with a firm plaque of exudate. Such $\frac{a}{0}$ mistake was made in the first case in this series, where a confident diagnosis of carcinoma of thes cæcum was made, and a right hemi-colectomg performed. Recovery from the operation seemeg to be complete when, a fortnight later, the patient suddenly collapsed. A further operation wos performed, when he was found to have a massive infarction of his small intestine. This was rer sected, but he unfortunately succumbed. The cause of the infarction was never ascertaine $\$$ In each of the other five cases the diverticulum was carefully dissected and removed, with uneventfa recovery.

Perforated diverticulitis of the distal colon probably always an acquired condition, occurning most often in stout elderly women. The average age in this series was 67 , and there were five cases over 8o. The term is really a misnomer, and 8 loosely applied to three quite separate entities. Firstly there is the single acutely inflamed dive $\vec{E}$ ticulum which has perforated, and which loo like a perforated appendix and can be treat similarly. This is the rarest type, only one bein found in the present series. The second is the perforated pericolic abscess, where the peritoneat cavity is full of pus, and the sigmoid colon acutery inflamed and swollen, but no free fæcal material present, and no demonstrable perforation. Th is the commonest type. Finally there is the large perforation, clearly visible and with the peritoneat cavity swamped with frank fæces. This is, of course, the moşt lethal type and accounts for most of the fatalities. In our opinion this is the onB type in which colostomy is required, and although we were using other forms of treatment in the earm. cases in this series, in the last nine cases without obvious fæcal contamination we have employed simple drainage, and had only two deaths-both in people over 80 years old. Very old people do not stand prolonged operations, and (Ryan, I95\& Staunton, 1962; Beard and Gozer, 196I) although radical excision, with or without colostomy may be the ideal form of treatment, we are convinced that the less surgery that is done, the more patients wiII survive. Regarding subsequent 'cold' bow resection for the segment involved, it is significa 
that of the 17 cases in our series who survived without resection, only two had to be later readmitted for an elective resection.

The results in accordance with treatment and age appear in Table 5 .

TABLE 5

Perforated Diverticulitis of Sigmoid Results According to Treatment

\begin{tabular}{cccc|c|c}
\hline & & Cases & Deaths \\
\hline Drainage only & $\ldots$ & $\ldots$ & $\ldots$ & 9 & 2 \\
Drainage and removal of diverticulum & & I & - \\
Drainage and colostomy & $\ldots$ & $\ldots$ & 7 & 2 \\
Drainage and closure of perforation & 2 & - \\
Paul-Mickulicz resection & $\ldots$ & $\ldots$ & I & I \\
Hartmann's resection & $\ldots$ & $\ldots$ & I & - \\
\hline Total & $\ldots$ & $\ldots$ &.. & 2 I & 5 \\
\hline
\end{tabular}

Results According to Age

\begin{tabular}{|c|c|c|c|c|}
\hline Age & Males & Females & Total & $\overline{\text { Deaths }}$ \\
\hline $40-49$ & 2 & 2 & 4 & - \\
\hline $50-59$ & 3 & I & 4 & - \\
\hline $60-69$ & I & 2 & 3 & - \\
\hline $70-79$ & - & 5 & 5 & 2 \\
\hline $80-89$ & - & 5 & 5 & 3 \\
\hline
\end{tabular}

It is worthy of notice that there were no deaths among the II patients under the age of 70.

\section{Summary}

An eight-year personal series of common acute abdominal emergency operations at a small nonteaching hospital, has been described. The series has included $72 \mathrm{I}$ cases of acute appendicitis, 81 cases of perforated peptic ulcer, 120 cases of acute intestinal obstruction and 27 cases of perforated diverticulitis of the colon. The improvement in surgical results that has been achieved with the aid of better pre- and post-operative manage- ment, careful use of antibiotics and chemotherapy is evidenced by the fact that of the 698 cases in this series who were under the age of 50 there were only two deaths-the young girl who had a gangrenous appendix coinciding with the end of her pregnancy, and the young man who died of cardiac arrest on the operating table as a result of bilateral phæochromocytomata.

Emphasis is laid on the importance of treating many abdominal emergencies conservatively, and thus avoiding unnecessary operations at all ages, and unnecessary fatalities in the aged. More attention should be given to the rather different surgical approach that is needed in dealing with elderly patients in a population where these people are forming a larger and larger share of our hospital patients. If we exclude acute appendicitis, which is predominantly a disease of the young, we find that of the 227 emergency abdominal operations described in this paper, no less that 86 , or $37 \%$, were in patients beyond the age of 70 ! It should be a cardinal rule when treating very old people to avoid operation altogether if possible, and if operation is unavoidable, then to make the operation as short as possible. There were 25 patients over the age of 80 in this series, and the fact that 16 survived despite the grossest pathology was a tribute to conservative surgery, antibiotics and excellent anæsthesia.

I should like to thank Mr. Maurice Lee and Mr. Raymond Ramsay under whose care the majority of these cases were admitted; the theatre staff and ward sisters for their never-failing cheerfulness and co-operation; Dr. Tom Kimmet and several other anæsthetic registrars for an unending series of excellent anæsthetics, without which these operations could certainly never have been performed. I should like to thank the Records Department for helping me with the arduous task of collecting all these cases. Finally I should like to thank Sir Zachary Cope, whom we all regard as the doyen of emergency surgery, who was kind enough to read through the rough draft of this paper and offer much advice and encouragement.

\section{REFERENCES}

Beard, R. G., and Gozer, J. C. (196r): 'Perforated Diverticulitis of the Colon with General Peritonitis', Guy's Hosp. Rep., I10, 263.

Ryan, P. (1958): 'Emergency Resection and Anastomosis for Perforated Sigmoid Diverticulitis', Brit. J. Surg., $45,6 \mathrm{II}$.

Staunton, M. D. M. (1962): 'Treatment of Perforated Diverticulitis Coli', Brit. med. F., i, 916. 